\title{
The potential role of forensic pathologists in veterinary forensic medicine
}

\author{
Roger W. Byard · Wayne Boardman
}

Published online: 17 April 2011

(C) Springer Science+Business Media, LLC 2011

There has been an increasing awareness over recent years of the field of veterinary forensic medicine, with involvement of veterinarians in a wide range of activities extending from the assessment of possible inflicted injuries in domestic animals to wildlife crime concerning the entrapment, transport and killing of protected and endangered species [1,2]. More publications are occurring in this area, with for example, a special issue of Forensic Science Medicine and Pathology being recently devoted to wildlife crime, and comprehensive textbooks now emerging [2-4]. The opportunity for forensic pathologists to contribute to this area is also being increasingly recognized [5].

The link between human forensic pathology and that involving animals is obvious and the opportunity to foster collaboration between these two areas of practice should be seized upon, as information and techniques utilized by forensic pathologists may be of great use in veterinary practice. As forensic pathologists are exposed on a daily basis to lethal injuries and processes, they also have a wealth of information that can be shared with veterinary colleagues who may not have such intense exposure to this type of material.

R. W. Byard ( $\square)$

Discipline of Anatomy and Pathology, Level 3 Medical School

North Building, The University of Adelaide, Frome Road,

Adelaide 5005, Australia

e-mail: roger.byard@sa.gov.au

W. Boardman

School of Animal and Veterinary Science, The University

of Adelaide, Frome Rd, Adelaide, Australia

R. W. Byard - W. Boardman

The Australian Marine Wildlife Research and Rescue Organisation (AMWRRO), Torrens Island, Adelaide, SA, Australia
It is quite obvious that forensic pathologists with training in human disease and injury have a great deal to learn from veterinary colleagues, and that many of the dissections and conditions encountered will be completely outside their experience. However, certain conditions affecting both humans and animals may show common features, and as lethal episodes in humans may have been studied more extensively than in non-humans, cross-species comparison of cases may provide a useful guide for the possible investigation of nonhuman fatalities. A good example of this was a young adult male Indian Ocean Bottlenose dolphin (Tursiops of aduncus) that was found dead with a small Cobbler Carpetshark (Sutorectus tentaculatus) wedged firmly within its upper aerodigestive tract. Known as café coronary syndrome in humans, this type of death raised the possibility of neurological impairment and prompted a search for intrinsic central nervous system disease, or heavy metal poisoning in the affected animal [6].

The use of human imaging modalities, such as CT scanning, in animals with significant injuries may demonstrate more clearly the nature of the injuries than standard dissection or skeletal defleshing. For example, comminuted fracturing of the midfacial skeleton in a juvenile New Zealand fur seal (Arctocephalus forsteri) was far more clearly shown by CT scanning prior to necropsy than afterwards, as the delicate central facial skeleton had collapsed once supporting fascia and soft tissues had been removed [7]. Unfortunately techniques routinely used in humans, such as immunohistochemical staining of tissues for microscopy using anti-human reagents may not always work in animals [8], although on occasion there may be a surprising degree of cross reactivity [9].

Another area that forensic pathologists can contribute to is in lecturing to veterinary science students on basic injury assessment and evaluation. A patterned abrasion, a stab 
wound, or a laceration all have diagnostic features that are independent of the victim's species. Forensic assessment of animal injuries may assist, therefore, in determining the likely sequence of events that led to an injury and the type of weapon involved. In addition, there may be significant information on the cause, mechanism and manner of death that may have considerable legal significance in cases of inflicted trauma, and so lecturing on basic medicolegal processes, expert evidence and the court system can be extremely useful. An awareness of the features of inflicted injuries in animals is important for veterinarians, as such cases are not rare [10] and may on occasion involve complex human psychopathology such as in cases of factitious illness by proxy [11].

Collaboration at the time of necropsy is often extremely useful, with forensic pathologists being able to assist with determinations as to whether wounds were inflicted ante or post-mortem, what may be a possible cause of death, and what changes may be due to autolysis or putrefaction. Histological follow-up may also be an adjunct to the analysis of cases. In addition, the types of tests that are routinely performed in human forensic cases such as microbiological or toxicological studies may also have a role in animal deaths. Cases where human victims have succumbed to a dog attack are an example of a situation where veterinary studies may assist human investigations, as a necropsy of the offending animal may provide information helping to establish the identity and ownership of the animal, as well as trace evidence linking the dog to the victim [12].

There seems to be an excellent opportunity at present for forensic pathologists with a back ground in human disease and injury to collaborate with veterinary colleagues in the assessment of animal injuries and causes of natural and unnatural, sudden and unexpected deaths. Multidisciplinary approaches often strengthen pathological opinions, independently of the species under investigation.

\section{References}

1. Cooper JE, Cooper ME. Forensic veterinary medicine: a rapidly evolving discipline. Forensic Sci Med Pathol. 2008;4:75-82.

2. Wilson-Wilde L. Combating wildlife crime. Forensic Sci Med Pathol. 2010;6:149-50.

3. Linacre A, editor. Forensic science in wildlife investigations. Boca Raton: CRC Press; 2009.

4. Cooper JE, Cooper ME. Introduction to veterinary and comparative forensic medicine. Oxford: Blackwell Publishing; 2007.

5. Byard RW, Gilbert JD, Kemper CM. Dolphin deaths: forensic investigations. Med J Aust. 2001;175:623-4.

6. Byard RW, Gilbert JD, Gibbs SE, Kemper CM. Cetacean café coronary. J Clin Forensic Med. 2003;10:85-8.

7. Byard RW, Machado A, Braun K, Solomon LB, Boardman W. Unexpected deaths in captive juvenile New Zealand fur seals (Arctocephalus forsteri). Forensic Sci Med Pathol. 2010;6: 217-20.

8. Byard RW, Tomo I, Kemper CM, Gibbs SE, Bossley M, Machado A, Hill M. Unusual causes of fatal upper aerodigestive tract obstruction in wild bottlenosedolphins (Tursiops aduncus). Forensic Sci Med Pathol. 2010;6:207-10.

9. Byard RW, Carli M, Moore A. An immunohistochemical study of the southern hairy-nosed wombat (Lasiorhinus latifrons). Ch 3. In: Wells RT, Pridmore PA, editors. Wombats. Chipping Norton: Surrey Beatty \& Sons; 1998. p. 42-47.

10. Munro HM, Thrusfield MV. 'Battered pets': features that raise suspicion of non-accidental injury. J Small Anim Pract. 2001; 42:218-26.

11. Munro HM, Thrusfield MV. 'Battered pets': munchausen syndrome by proxy (factitious illness by proxy). J Small Anim Pract. 2001;42:385-9.

12. Tsokos M, Byard RW, Püschel K. Extensive and mutilating craniofacial trauma involving defleshing and decapitation. Unusual features of fatal dog attack in the young. Am J Forens Med Pathol. 2007;28:131-6. 